\title{
SENTIDO EPISTÉMICO DE LA MÚSICA EN EL DE MUSICA, LIBER VI DE SAN AGUSTÍN \\ John G. Lazos*
}

RESUMEN: El último volumen del primer tratado sobre la música, De musica, liber VI de san Agustín, había permanecido prácticamente en el olvido. Afortunadamente, el trabajo escrupuloso de Martín Jacobsson, recupera la esencia original de esta obra, donde la música se muestra como una metáfora de mediación con el discurso racional. Este ensayo compara dichas referencias, el lugar de la música dentro del quadrivium y analiza el concepto de hombre ante su planteamiento epistémico con que da cuenta de la naturaleza de la música.

$$
\text { sose }
$$

ABSTRACT: The last volume of the first treatise about music, saint Augustine's De musica, liber VI, had been lost to the oblivion. Martin Jacobsson's meticulous work luckily recovers the original essence of this work, in which music is a metaphor of mediation with the rational discourse. This article compares such references, the role of music in the quadrivium and analyzes the concept of man when faced with this epistemic approach to the nature of music.

PALABRAS CLAVE: música, epistemología, quadrivium, san Agustín, Jacobsson. KEY WORDS: music, epistemology, quadrivium, saint Augustine, Jacobsson.

RECEPCIÓN: 28 de octubre de 2010.

APROBACIÓN: 11 de octubre de 2011.

*Université de Montréal (Faculté de Musique). 
La reproducción total o parcial de este artículo se podrá hacer si el ITAM otorga la autorización previamente por escrito. 


\section{SENTIDO EPISTÉMICO \\ DE LA MÚSICA EN EL \\ DE MUSICA, LIBER VI \\ DE SAN AGUSTÍN*}

\section{Acercamiento a una obra en el olvido}

\section{San Agustín (354-430), obispo de}

Hipona (hoy Annaba, al noreste de Algeria), es reconocido como Padre de la Iglesia por haber sentado las bases de la institución cristiana: la unión entre la fe y la razón. A partir de la comunión entre su vida y sus escritos, Agustín traza el camino que la tradición occidental, tanto en la Iglesia como en la filosofía, ha enmarcado desde el siglo cuarto de nuestra era. La alianza entre su profunda devoción y la fuerza de su pensamiento filosófico son claros en dos de sus obras más conocidas: Confessiones y De civitate Dei. Empero, de no menor atención es el De musica, cuyo último volumen es probablemente el más antiguo en su materia, escrito alrededor del año 386, justamente dos años después de haber conocido a Ambrosio, obispo de Milán, de quien recibiera el sagrado ritual del bautismo. ${ }^{1}$

A pesar de que las obras de Agustín integran un extenso corpus literario, pacientemente sigue la espera de una compilación completa de sus obras en lengua moderna. ${ }^{2}$ Resulta especialmente difícil encon-

* Quisiera agradecer las sugerencias y colaboración de María Eugenia Herrera Azoños en la preparación de este ensayo.

${ }^{1}$ Algunas fuentes lo ubican en el 388 d.C., véase Francis Ferrier, San Agustín, 1996, México, Conaculta, trad. de Sofía Miselem, p. 31.

${ }^{2}$ Catálogos de los manuscritos de todas las obras de Agustín se publican por la Österreichische Akademie der Wissenschaften en Viena, véase Martin Jacobsson (tr. y ed.), “Aurelius Augustinus, 
JOHN LAZOS

trar ediciones que contengan siquiera alguna sección de su tratado intitulado De musica, libri VI. Tanto, que las referencias especializadas aluden escuetamente al sexto y último volumen, el liber VI, inclusive desde aquel remoto pasado en el que fue concebido. Generalmente, estas referencias no van más allá de mencionar su existencia, por lo que la obra y su contenido han caído prácticamente en el olvido; de esta manera, se pierden en el discreto silencio seis libros dedicados enteramente a la música.

Como punto de partida, entre las referencias contemporáneas al De musica, liber VI, hay que considerar a Michael Bernhard y Henri Ireneé Marrou. ${ }^{3}$ Con sus indicaciones, Bernhard y Marrou posibilitan un acercamiento, al menos parcial, al liber VI. Me planteo desarrollar un diálogo crítico y pasar a una lectura puntual del escrupuloso trabajo de investigación de Martín Jacobsson, el cual presenta el texto latino original, con traducción al inglés, del tratado completo del De musica, liber VI. De esta manera, el presente ensayo constituye una contribución a los estudios de historia sobre los escritos musicales y hacia la especulación sobre la disciplina de la música.

\section{El lugar de la música en el quadrivium}

Ambiciosa empresa, en la que De musica fue originalmente concebida como una parte del conjunto de los tratados que Agustín dedicaría a cada una de las siete artes liberales, a saber, del trivium (dialéctica, gramática y retórica) y del quadrivium (aritmética, geometría, música y astronomía). Sin embargo, además del tratado dedicado al estudio de la música, la única obra en la que el autor llevó a cabo su propósito inicial, tuvo como tema la gramática.

De musica liber VI", Acta Universitatis Stockholmiensia, Studia Latina Stockholmiensia 47, 2002, p. $\mathrm{xxx}$.

${ }^{3}$ La referencia de Michael Bernhard aparece en el capítulo titulado "'Glosses on Boethius'. De Institutione musica", en André Barbera (ed.), Music Theory and its Sources, Antiquity and the Middle Ages, 1990, Notre Dame, University of Notre Dame Press; la de Henri Irénneé Marrou, en el apéndice de su disertación del año 1938; véase Jacobsson, op. cit., p. Xv-xviii; también Ferrier, op. cit., p. 5. 
Se asume como hecho que las artes liberales tenían como principal propósito guiar al estudioso prospecto; más precisamente, lo que se plantea abarca mucho más que transmitir conocimientos y desarrollar habilidades. Se puede afirmar que las disciplinas fueron concebidas justamente para conformar el carácter y perfil del candidato: de disponerlo al conocimiento del mundo, de sí mismo y de Dios. Hay un orden entre las disciplinas que responde a la naturaleza de su asunto, a su función epistémica y al proyecto de formación, que lo vuelve algo más complejo que una simple actividad didáctica. Este orden cognitivo plantea, ya desde la enumeración de las disciplinas, el lugar determinado que cada una habrá de ocupar.

Aunque Martianus Capella, contemporáneo de Agustín, ubica a la música en la última posición de su esquema, la norma era colocarla entre la segunda o, todavía más frecuente era en el tercer lugar de los cuatro estudios del quadrivium. ${ }^{4}$ Lo cierto es que, independientemente del lugar exacto, no fue concebida para ser el primer tema, el introductorio, dentro del cuerpo de las artes liberales.

Para ser más preciso, el sentido que tiene para Agustín responde a que, tanto la aritmética - que versa sobre los números y las medidas-, como la geometría - que toma por asunto las formas-, se ocupaban de lo tangible, mientras que la astronomía ostentaba el máximo grado de abstracción. Así, la música funge como articuladora entre las primeras disciplinas terrenales, y de ésta última, la celestial. A partir del reconocimiento del carácter vinculante de la música, con respecto a las otras disciplinas del quadrivium, el planteamiento que presenta Agustín sobre el sentido epistémico puede describirse a partir del De musica, liber VI.

\section{El interés de los antiguos en el De musica, liber VI}

En una carta que data de los años del 408 y 409 -y varios después de haber escrito De musica-, Agustín envía a su compañero, el obispo

${ }^{4}$ Véase Edward Lippman, The Philosophy and Aesthetics of Music, 1999, Lincoln \& London, University of Nebraska Press, pp. 84-98. 
JOHN LAZOS

Memorius, el último de sus seis libros: De musica, liber VI. De los seis que fueron escritos sobre música, el último atrajo más vivamente la atención e interés de los contemporáneos del autor; inclusive encaminado a su crepúsculo, Agustín recopila en Retractationes un catálogo de su vida, en el que revisa cuidadosamente su corpus literario. De esta manera, y como testimonio del mismo autor, queda claro que el último libro "se convirtió en el más conocido y leído de los primeros cinco". 5

De esto se puede seguir la distinción personal que hacía el mismo Agustín entre los primeros cinco libros y el sexto. Lo que se sabe al respecto, gracias a las alusiones de Marrou y de su renombrado texto dedicado a Agustín -en el que sólo dedica cuatro páginas al liber VI-, ${ }^{6}$ es que existe una diferencia temática entre los primeros cinco libros y el último: los primeros tratan de aspectos concernientes a medidas científicas y numéricas ( $\dot{v} \vartheta \mu$ ós), mientras que el sexto se ocupa de "temas filosóficos y religiosos, hasta "eclesiásticos"". 7 Por lo tanto, el sexto y último libro fue enmarcado, aislado y distanciado de los otros desde sus mismos orígenes hasta los tiempos de sus más recientes lecturas.

\section{Dos alusiones de Bernhard al De musica}

A pesar de que se tienen noticia por el propio Agustín del interés peculiar que había en el De musica, liber VI, por otro lado resalta que las referencias literarias a esta obra sean tan discretas como raras de encontrar, abarcando aun las fuentes actuales de historia sobre los estudios de música; en Music Theory and its Sources: Antiquity and the Middle Ages, el De musica de Agustín es mencionado solamente un par de veces: en una, sobre lo que trata; en la otra, lo que aparentemente plantea. Bernhard menciona que el "libro sexto trata sobre asuntos estéticos y religiosos, particularmente sobre la relación del alma con Dios, todo dentro de la orientación neoplatónica cristiana. Las consideraciones estéticas y morales del sexto libro se basan en conceptos neoplatóni-

${ }^{5}$ Jacobsson, op. cit., pp. xiv, lxiii. Salvo indicación específica, las traducciones son mías.

${ }^{6}$ Véase Henri-Irénnée Marrou, Saint Augustin et la fin de la culture antique, 1958, Paris, E. de Boccard. 1958, pp. 580-3.

${ }^{7}$ Idem, p. xv. 
cos de belleza y bondad como resultado de la correcta presentación de las proporciones matemáticas"; agrega más adelante, en forma de conclusión: "este tratado no informa sobre las prácticas musicales en los tiempos de Agustín". 8

Considerar estas referencias de Bernhard como un acercamiento confiable al texto de Agustín llevaría a inferir que el contenido del liber VI no va más allá del desarrollo de un marco de pensamiento neoplatónico, al tiempo de carecer de alguna aproximación al tema de la música per se. De tal suerte, Bernhard parecería dar pocos motivos para buscar en Agustín algo más que una curiosidad lejana de un pasado ya remoto.

Antes de presentar las aportaciones teóricas de Agustín sobre el tema de la música y de su función especulativa, de la cual ya era parte vital dentro del esquema de las artes liberales, hay que acotar el apresurado reduccionismo en el que se ha enmarcado a Agustín como un mero neoplatónico, un platónico cristiano.

\section{Una sana dosis de Aristóteles en Agustín}

Hay que recordar que separan a Platón y a Agustín más de siete siglos. Esto sugiere ya que la apropiación que hace Agustín del pensamiento de Platón está mediada, inevitablemente, por la discusión desarrollada por otros filosófos, en particular mediante las obras de Plotino, a quien Agustín leyó durante su estancia en Milán, poco antes de comenzar a escribir su tratado De musica. Así, la influencia platónica acontece a partir de una coyuntura distinta de la del pensamiento del mismo Platón, por lo cual, sin duda incorpora conceptos y problemas que no son propiamente platónicos. ${ }^{9}$ Habría que seguir en Agustín, junto al legado de Platón, el de Aristóteles, latente durante el curso de la tradición y particularmente durante el Medioevo.

Constituye una miope aproximación interpretativa limitarse a reconocer a Platón como la única influencia filosófica en Agustín; ver en

${ }^{8}$ Music Theory and its Sources..., op. cit., pp. 123-4.

${ }^{9}$ Véase Ferrier, op. cit., p. 25. 
él un epígono de Platón dificulta, de entrada, atender la pretensión de verdad del propio tratado; se encubre así el hecho de que Agustín construye su pensar apropiándose de su tradición filosófica, tradición que ciertamente no comprende únicamente a Platón. Para ampliar nuestras posibilidades de un acercamiento fructífero al De musica, liber VI, hay que cuidar el campo de la especulación literaria.

Consideremos, sin estrechar nuestra interpretación, que la insospechada influencia que hay de Aristóteles en Agustín ha sido mencionada, entre otros filosófos, por Hans-Georg Gadamer quien, sin titubeos, afirma el hecho de que "ha sido establecido que Agustín, el platónico cristiano, tuvo una sana dosis de Aristóteles. Y el mismo punto ha sido establecido en orden inverso: la tradición del platonismo agustiniano fue completamente capaz de preservarlo, por sí mismo, durante el tiempo en que la aceptación por Aristóteles fue gradualmente creciendo en la Edad Media". ${ }^{10}$

Independientemente de indagar cuáles filósofos han enmarcado el pensamiento de Agustín, su obra como parte de la corriente de los escritos musicales, nos invita a especular sobre la disciplina de la música y tratar al último libro de Agustín como un tratado sobre su estudio. De esta forma, es necesario colocar las referencias de Bernhard bajo sospecha, para proceder a hacer una nueva lectura del antiguo tratado que se nos ofrece a partir de la valiosa aportación de Jacobsson.

\section{El acceso a la fuente de Martin Jacobsson}

Pareciera sorprendente, pero se cree que el manuscrito más antiguo del que se tiene conocimento data de fines del siglo VIII o principios del IX, es decir, desde que Agustín escribiera De musica, a fines del siglo IV, tuvieron que transcurrir aproximadamente cuatro siglos hasta poder dar cuenta del primer testimonio físico de su existencia. El más antiguo de estos manuscritos se haya en el Monasterio de Saint-Martin, en Tours. En la actualidad, sólo el libro sexto aparece, ya sea en su

${ }^{10}$ Hans-Georg Gadamer, Dialogue and Dialectics, Eight Hermeneutical Studies on Plato, 1980, New Haven and London, Yale University Press, transl., and ed. Christopher Smith, pp. 194-5. 
totalidad, ya fragmentado, en setenta y ocho diferentes manuscritos, de los cuales treinta y ocho han sido localizados, recopilados y comparados gracias a la afortunada y escrupulosa investigación de Jacobsson. Dichos manuscritos corresponden a poco más de la mitad del total, que incorpora a los más antiguos, del siglo VIII, hasta los menos, del siglo XV. Un acierto elemental acerca de la antigüedad del material que Jacobsson nos presenta en su disertación es que todavía existen ciertas sospechas sobre la autenticidad del más antiguo, ya que "es verdad también que no sabemos [...] que pasó con los siguientes cuatrocientos años entre los tiempos del autor y la evidencia del más antiguo". ${ }^{11}$

La importancia del trabajo de Jacobsson estriba, además, en que hace la obra accesible, al presentarla al lector en el original latino y su traducción al inglés. A partir de esta edición, y de las que habrán de llegar en otras lenguas, se pone a prueba la lectura de Bernhard. ${ }^{12}$ Cabe señalar que una ventaja considerable es el original latino, pues permite al lector seguir la terminología propia del autor y profundizar en los mismos terrenos originales de interpretación. Ya sea que se considere al latín una lengua muerta desde hace siglos, y por ello sustraído al continuo y activo movimiento del habla, hay que decir que las ideas de su autor han sido conservadas en su espíritu original y, al mismo tiempo, se nos dispensa del extenso laberinto de las múltiples traducciones.

\section{El asunto del De musica, liber VI}

\section{El diálogo, la música y el hombre}

En su lectura, Agustín presenta el De musica, liber VI bajo la forma de un diálogo entre el magister y su discípulo. Naturalmente, esto se debe en parte a la tradición platónica de argumentar las ideas, de construir el discurso racional ( $\lambda$ ó $\gamma$ os). Dentro de ella, en el modelo paradig-

${ }^{11}$ Jacobsson, op. cit., p. cxiv.

${ }^{12} \mathrm{Al}$ momento de preparar este ensayo tuvimos noticia de que la primera edición en castellano del De musica, liber VI, dirigida por Cecilia Ames, Darío Sánchez y Diego Márquez, apareció en Alción Editora, Argentina, en el año 2000. 
JOHN LAZOS

mático del diálogo platónico, es Sócrates quien suele dirigir la discusión, interrogando hasta el agotamiento a sus interlocutores, generalmente los no bien afamados sofistas o sus discípulos, con el sólo propósito de develar la verdad (otrora $\alpha \lambda \eta \eta ́ \vartheta \varepsilon \iota \alpha$ ) a través de la tensión entre los discursos que plantean estas problemáticas. En el caso de este diálogo, el desvelamiento de la verdad no se realiza por medio de una tensión entre discursos, sino como el despliegue reflexivo en que el maestro conduce a su discípulo por el camino del conocimiento de lo corpóreo a lo incorpóreo. El discípulo no está aquí para refutar o para ser refutado; más bien constituye una agradable compañía que, con sus simples preguntas retóricas y obvias interpelaciones, ofrece la ocasión a su maestro de desplegar su articulado pensamiento.

De musica, liber VI comienza por recapitular lo que concierne a los anteriores volúmenes, ya que "de manera infantil, nos concentramos en los cinco libros, en los ritmos que pertenecen a la duración de los tiempos". ${ }^{13}$ Agustín no deja lugar a dudas, desde la primera línea del sexto libro, que ya no tratará el susodicho 'pueril' argumento, referente al tema de los números. Lo que Agustín ansiaba explicar ahora era su concepto del hombre; precisamente ahí habrá de aterrizar su trabajo especulativo: desarrollar su idea por medio del estudio de la música es la razón por la cual plantea su reflexión, como parte final de las disciplinas del quadrivium. Es posible porque la música es la única que se relaciona con los otros estudios en la misma proporción en que el hombre se relaciona con ella. Lo dicho no es novedad dentro del contexto del pensamiento agustiniano; la tentación de mediar a través de la música ha estado presente desde los griegos. En palabras de Edward Lippman, “es Platón el que más aprecia en general el papel de la música y quien al mismo tiempo profundiza dentro de las bases teóreticas la interconexión con la 'mathemata.' La música se convierte en la última disciplina porque es la más general y la que mejor explica la total naturaleza de las matemáticas". ${ }^{14}$

Para reconocer el peculiar papel de la música como interconexión epistémica en Agustín hay que considerar lo siguiente: el resto de las

${ }^{13}$ Jacobsson, op. cit., p. 6.

${ }^{14}$ Lippman, op. cit., p. 85. 
disciplinas se relacionan con el hombre en que explican lo que está ahí, en la llamada realidad presente: el orden y las proporciones de las cosas, los objetos y las formas; el hombre como punto de partida para entender y explicar su realidad inmediata. Se entienden las cosas, los objetos, como la realidad dada, expresada mediante las diferentes funciones epistémicas de las disciplinas; esto es, lo que las disciplinas permiten entender y construir explicando está de manifiesto ahí. Para esclarecer el antecedente teórico de esta mediación, hay que recordar que la búsqueda de la verdad, patente en los diálogos de Platón, se planteaba mediante la figura de Sócrates, como el esfuerzo portentoso cuya metáfora se consolidó en el laborioso proceso de alumbrar, la vocación del alumbramiento de la $\alpha \dot{\lambda} \eta \dot{\vartheta} \iota$ เ $\alpha$. De aquí, se sostiene que la verdad era descubierta a expensas del hombre mismo; era posible desvelar la verdad porque ésta es alcanzable por medio de la pregunta correcta, sustraída a expensas de aquellos que se debatían por responder.

El papel del hombre como mediación en el descubrimiento de la verdad corresponde aquí a la metáfora de la música. Si la música, en tanto obra sonora, tiene la posibilidad de acontecer por la acción mediante el intérprete, es precisamente porque el elemento sonoro está manifestado por su presencia en el carácter mismo del músico, el cual inequívocamente adopta el nombre del ejercicio que corresponde a su práctica; esto lo entendía ya Boethius: "el hecho de que aquellas personas - los llamados así por sus talentos físicos- toman el nombre no por la disciplina [que ejercen], sino más bien por el instrumento". ${ }^{15} \mathrm{~A}$ partir de esto, se explica a la música como la disciplina de la metáfora límite de la mediación sonora, de la interconexión entre saberes y órdenes de lo real, sustraída de la práctica del mismo ejecutante de un instrumento, y en ello, se indaga especulativamente por su naturaleza.

La música como disciplina no termina de explicarse mediante el intérprete, quien por sí mismo presenta el arte sonoro a partir de su técnica ( $\tau \dot{\varepsilon} \chi \vee \eta)$, o por lo que referimos como su oficio; es decir, en el discurso racional ( $\lambda$ ó $\gamma$ ○) radica la posibilidad de explicar y entender

${ }^{15}$ A. M. S. Boethius, Fundamentals of Music, 1989, New Haven \& London, Yale University Press, tr., int. and notes Calvin M. Bower; ed. Claude V. Palisca, p. 50. 
JOHN LAZOS

lo que concierne a la relación entre el hombre y su realidad, mediante la trascendencia de la música como disciplina, como ya lo había descrito Platón en el diálogo de Las Leyes: "Aún más, como ya lo he dicho tantas veces, aquel que no ha contemplado la naturaleza de la mente, que ya se ha dicho existe en las estrellas, y a través del entrenamiento previo, y vea la conexión de la música con estos asuntos, y armonizarlos con las leyes e instituciones, no le es permitido dar razón de tales asuntos como el tener la razón". ${ }^{16}$

Entonces, a partir de la música misma, Agustín fundamenta el corpus de las artes liberales, construyendo su articulación intelectual, vía que soporta mediante el sentido epistémico de la música desde su concepto de hombre en el liber VI. Para mostrar esto, es preciso examinar gradualmente tal estudio, atendiendo a que la música es ya parte de una presencia objetiva, pues se halla en la naturaleza de las cosas y en presencia de la naturaleza del hombre mismo, representado en el personaje del músico como intérprete de un instrumento.

\section{Los cinco géneros del elemento de la música}

Mientras que durante los primeros cinco libros del De musica se ha construido el camino de la reflexión con los gramáticos y los poetas por medio del ritmo, en el sexto y último libro se concentra como ejemplo paradigmático el verso de su buen amigo Ambrosio como punto de partida, el cual es, al mismo tiempo, la única referencia que no proviene de la Biblia. Aquí, el verso del viejo compañero de Agustín: Děūs crěātŏr ōmnūūm, no sólo muestra una estructura propia, sino que construye ya un signo del alcance de este análisis que se emprende a partir de la pregunta propia por el ritmo. La pregunta por el ritmo desde el verso interroga aquí por las relaciones en que se encuentra el elemento natural de la música.

II.2. Así que, contéstame, si te place, amigo mío, con el cual estoy ahora discutiendo, para que así podamos desplazarnos desde lo corpóreo

${ }^{16}$ Lippman, op. cit., p. 85. 
a lo incorpóreo: cuando pronunciamos el verso Deus creator omnium, ¿dónde crees que estos cuatro [versos] yámbicos, del cual consiste, y de los doce tiempo-unidad que son, es decir, deberíamos decir que estos ritmos están solamente en el sonido que escuchamos, o también en el sentido auditivo, que pertenece a los oídos, o también a la actividad de la persona que pronuncia, $\mathrm{o}$, desde que el verso que es conocido, también en nuestra memoria? ${ }^{17}$

En este paradigmático párrafo introductorio se plantean, en sucesivas preguntas, cuatro de los cinco géneros, así denominados por Agustín, en cuya relación central se encuentra el elemento sonoro de la música. El análisis de los primeros cuatro géneros permite comprender la relación entre lo córporeo y lo incórporeo, que culminará con el quinto y último género. Cada uno de los géneros marca un nivel en el proceso de conocimiento que concibe Agustín en su finalidad, lo que es su concepto de hombre. Los primeros cuatro géneros corresponden, respectivamente, al sonido, al sentido auditivo, al acto de pronunciación y a la memoria. Por el momento se dejará al último género para mas adelante.

El verso Děūs crěātŏr ōmnǐūm, en su primer movimiento corpóreo, se manifiesta en la distinguible presencia que deviene de su pronunciamiento, a través de la mediación del sonido, sin dejar ningún espacio ausente cuando escuchamos el verso al ser pronunciado. El verso que se muestra en sonido causa una reacción (passione) física que es recolectada y testificada por el oído. Así, se turna la otrora presencia corpórea en una manifestación y presencia incorpórea, porque dicho verso ha sido ya pronunciado, dejando inmediatamente, tras su primera impresión corpórea, un amplio y claro silencio. Del primer al segundo género, el verso de Ambrosio ha mediado, como cualquier sonido capaz de ser escuchado, a ser inmediatamente recolectado, al ser pronunciado, por el sentido del oído (audientis), como una reacción (passione)

${ }^{17}$ Jacobsson, op. cit., p. 8: “II.2. Quam ob rem tu, cum quo mihi nunc ratio est, familiaris meus, ut a corporeis ad incorporea transeamus, responde, si uidetur, cum istum uersum pronuntiamos Deus creator omnium, istos quattur iambos, quibus constat, et tempora duodecim, ubinam esse arbitreris; if est, in sono tantum, qui auditur, an etiam in sensu audientis, qui ad aures pertinet, an in actu etiam pronuntiatis an, quia notus uersus est, in memoria quoque nostra hos numeros esse fatendum est?" 
JOHN LAZOS

hacía nuestro cuerpo, que logra reflejar el mencionado verso. A la presencia del silencio le siguen los cuatro ritmos yámbicos, "y deberíamos decir que los ritmos que están en relación con los oídos, cuando algo es escuchado, son tomados por su sonido y removidos en el silencio. Desde aquí uno podría concluir que los ritmos que existen en el sonido mismo pueden existir sin aquéllos en el escuchar, cuando el último no puede existir sin el primero". ${ }^{18}$

El cuerpo reacciona al verso en la misma proporción que el verso afecta al cuerpo; pero, ¿cómo es que el corpore reacciona al sonido del verso, o a cualquier otro sonido similar? El cuerpo lo hace porque reacciona (passione) mediante el alma (anima); este es uno de los puntos claves que explican el concepto de hombre en Agustín. El término original en latín sugiere una causante física implicada en una reacción corpórea, lo que se denomina aquí como alma, que se anima, precisamente, desde la contraparte corpórea, que en palabras de Gilson, refiere a que el "alma encuentra sentido cognitivo inmediatamente por encima del nivel de la vida misma. La doctrina de las sensaciones de Agustín es una de las teorías que nos permiten ver claramente qué es distintivo en su concepto de hombre". ${ }^{19}$

Es decir, las lenguas modernas no logran mantener el término original de Agustín, ya que debilitan susodicho vocablo, como el sentido inicial del que hace uso mediate el término de alma (anima), que se entiende en Agustín como la reacción del alma a través del cuerpo. En las lenguas romances no sólo se ha separado, sino también situado lejanamente el concepto del alma en la categoría de las puras manifestaciones espirituales. De esta manera, en su perenne y etérea presencia abstracta, el alma resulta ajena al cuerpo, ya que la toma como presa y como parte de las reacciones del mismo. Siguiendo con Gilson, el "alma humana es continuamente representada como un espíritu puro que ha caído y convertido en prisionero del cuerpo. Sin embargo, desde el principio, como se ha visto, el alma fue realmente creada como un deseo del cuerpo que anima (anima) por su unión desde entonces", ${ }^{20}$

${ }^{18}$ Ibid, p. 14.

${ }^{19}$ Etienne Gilson, The Christian Philosophy of Saint Augustine, 1960, New York, Random House, trans. by L.E.M. Lynch, p. 56.

${ }^{20}$ Idem, pp. 60-1. 
Agustín afirma que el alma reacciona por medio del cuerpo a los ritmos yámbicos del verso; así, el alma no está aquí desvinculada del cuerpo, sino que ha reaccionado mediante él, en este caso, hacia el patrón rítmico. Si el alma puede identificar entre los sonidos la correcta articulación del verso, es precisamente porque le es posible distinguirlo de cualquier otro sonido que no posee ninguna construcción rítmica; en el mismo plano que Agustín define la relación entre corpóreo e incorpóreo, no "debería ser todo lo que ocurre en el alma mejor concebido que cualquier cosa que ocurre en el cuerpo simplemente porque el alma es mejor que el cuerpo". ${ }^{21}$

El tercer género, el tercer nivel cognitivo que comenzó después del acto de pronunciar y de escuchar, se puede corrobar cuando el cuerpo reacciona al verso, logrando repetir de nuevo los ya mencionados ritmos yámbicos; el verso se convierte de nuevo en sonido, una imagen que representa el diseño original. Se reconoce en el pronunciamento del verso que ha reaccionado en el cuerpo de quien lo pronuncia, al reproducir el orden en que se representa en el alma. En este punto, Agustín está tan sólo a un paso de alcanzar el cuarto género, el relativo a la memoria, el cual sólo es posible alcanzar cuando los tres primeros han sido completados en orden.

Ser conscientes de este proceso - que va del primer al tercer género y equivale a la memoria, entendida aquí como repetición (mimesis)-, permite reconocer al verso cuando es nuevamente repetido. Volverse sobre el proceso cognitivo que inició con el verso lleva a representar la memoria como el cuarto género, que es el que da cuenta del proceso de rememorar los pasos que han llevado a los ritmos hasta su repetición: "contéstame sobre los tres tipos de ritmos, del cual uno es la memoria, otro la percepción, otro el sonido". ${ }^{22}$

La memoria retiene lo que ha resultado en el alma de los movimientos del oír y del pronunciar; finalmente, el quinto y último género es para Agustín el de la especulación, que permite tomar un paso objetivo fuera de los cuatro géneros previos y, desde ahí, dirigirse y verificar la

${ }^{21}$ Jacobsson, op. cit., p. 22.

${ }^{22}$ Idem, p. 38. 
JOHN LAZOS

manera en que éstos se han relacionado. El quinto da cuenta de cada uno de los anteriores porque estas reacciones han sido y son movimientos que toman parte en todo momento, inclusive en su abstracción, y tales movimientos son posibles de representar dentro de nuestro juicio natural de percepción -naturali iudicio sentiendi. Las huellas que quedan en la memoria, los llamados recuerdos, abren la posibilidad de que se vayan deteriorando o perdiendo en el transcurrir eventual del tiempo: "cualquiera que en esta memoria retenga desde los movimientos de la mente, que han sido activados hacia las reacciones del cuerpo, son denominados fantasía, $\varphi \alpha \nu \tau \alpha \sigma i \alpha$, pues no encuentro mejor término en latín". ${ }^{23}$

Fantasía es sólo uno de los cuatro términos griegos que Agustín emplea en su tratado de De musica, liber VI; a sabiendas de que Agustín no leía griego, aún así toma prestado dicho término de la tradición helenística por no encontrar mejor vocablo, el cual se entiende como "lo que aparece" o "se muestra". Las fantasías se producen en la memoria como rastros del movimiento del alma, reacciones que la propia alma llega a confundir a sí misma; es decir, las fantasías pueden reaccionar hacia sí mismas, produciendo sus propias imitaciones, como "confrontaciones con las reacciones del cuerpo e impresas por los sentidos, pero similares, como han sido, imágenes de imágenes, que he decidido denominarlos como $\varphi \alpha ́ v \tau \alpha \sigma \mu \alpha "{ }^{24}$

Por ello, el juicio (iudicio) toma la batuta para mostrar la diferen-

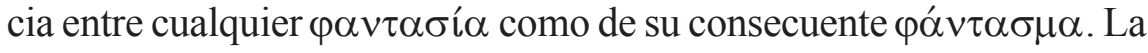
copia de la primera imagen, y las subsiguientes, son reacciones que no pueden ser evitadas, pero que pueden ser separaradas mediante el juicio de las demás impresiones que la memoria ha logrado representar. El juicio separa al afirmar y confirmar, en su correcta especulación, desde el $\lambda$ ó $\gamma$ os mismo.

Consecuentemente, la especulación sobre la naturaleza de la música y su sentido epistémico la muestra como fuente de autoconocimiento, al reconocer al hombre en el orden de lo existente, mostrando lo que se manifiesta como real, hasta la contemplación de la verdad por medio de su concepto de hombre.

${ }^{23}$ Idem, p. 68.

${ }^{24}$ Idem, p. 70. 


\section{Consideraciones finales}

Esta parva contribución a los estudios sobre los escritos musicales, iniciados con el De musica, liber VI de Agustín estriba, en resumidas cuentas, en los siguientes puntos: se ha ubicado al De musica, liber VI en el esfuerzo intelectual de Agustín por establecer la posición de la música en el quadrivium desde una perspectiva epistémica: la función de la música consiste en disponer al discípulo al conocimiento del mundo, de sí mismo y de Dios; se ha mostrado la manera en que Agustín se apropia de la tradición platónica, por la que reconoce en la música un carácter vinculante, que hace de ella metáfora límite de la mediación del orden de lo existente, del conocimiento y de las disciplinas; se ha señalado, por medio del breve análisis del término anima, la manera en que el concepto de hombre en Agustín soporta el planteamiento epistémico con que da cuenta de la naturaleza de la música; asimismo, se ha puesto de manifiesto también la relación entre la música, como metáfora de mediación, y el discurso racional. Se expuso, en breve síntesis, una lectura del De musica, liber VI, ofreciendo así al lector interesado en el tema un acercamiento al contexto y al contenido de la obra de Agustín; por último, se ha manifestado que la aportación de Jacobsson al del De musica, liber VI, convierte las alusiones de Bernhard en un precario acercamiento a esta obra, pues, más que instarnos a acceder a la fuente, parece dispensar de ello debido a su desinterés en el contenido de la obra y del reduccionismo respecto a las aportaciones de Agustín.

Finalmente, el De musica, liber VI de Agustín no sólo es una obra relevante para la historia de la teoría de la música: constituye también una posibilidad de repensar nuestros abordajes actuales sobre tal disciplina como un diálogo con nuestra tradición, en la medida en que podemos reconocer en el pensamiento de Agustín una de las fuentes de nuestras actuales preguntas por el sentido epistémico y estético de este antiguo arte. Espero que este trabajo pueda ser ocasión de reflexionar sobre la humana vocación del orden patente en la música y la forma de autoconocimiento que representa. 
La reproducción total o parcial de este artículo se podrá hacer si el ITAM otorga la autorización previamente por escrito. 